Article

\title{
New Insights on the Simultaneous Removal by Adsorption on Organoclays of Humic Acid and Phenol
}

\author{
Emese Szabó ${ }^{1,+}{ }^{+}$Zsolt Pap ${ }^{1,2,3, *,+}$, Gergó Simon ${ }^{1}$, András Dombi ${ }^{1}$, Lucian Baia ${ }^{3,4}$ and \\ Klára Hernádi ${ }^{1,5}$
}

Received: 23 August 2015; Accepted: 6 January 2016; Published: 18 January 2016

Academic Editors: Robert Puls and Robert Powell

1 Research Group of Environmental Chemistry, Institute of Chemistry, University of Szeged, Tisza Lajos krt. 103, HU-6720 Szeged, Hungary; eszabo@chem.u-szeged.hu (E.S.);

gsimon@chem.u-szeged.hu (G.S.); dombia@chem.u-szeged.hu (A.D.); k.hernadi@chem.u-szeged.hu (K.H.)

2 Faculty of Chemistry and Chemical Engineering, Babes-Bolyai University, Arany János 11, RO-400028 Cluj-Napoca, Romania

3 Faculty of Physics, Babes-Bolyai University, M. Kogălniceanu 1, RO-400084 Cluj-Napoca, Romania; lucian.baia@phys.ubbcluj.ro

4 Institute of Interdisciplinary Research in Bio-Nano-Sciences, Babeș-Bolyai University, Treboniu Laurian 42, RO-400271 Cluj-Napoca, Romania

5 Department of Applied and Environmental Chemistry, University of Szeged, Rerrich Béla tér 1, H-6720 Szeged, Hungary

* Correspondence: pzsolt@chem.u-szeged.hu; Tel.: +36-62-544-338; Fax: +36-62-544-619

+ These authors contributed equally to this work.

\begin{abstract}
The exploitation of thermal water as a heat source in houses and apartments (during winter) is a widely used alternative to natural gas. However, this type of water may contain organic contaminants, which must be removed before releasing the used water into rivers and lakes. Because of the presence of a wide range of pollutants (including phenolic compounds and humates), efficient, cheap removal processes are needed. In order to demonstrate their capability in thermal water cleaning, clay minerals were applied for the removal of phenol and humic acid via adsorption. To determine the most efficient removal strategy for the aforementioned pollutants, the following parameters were investigated: the type of the clay mineral, the organophilization strategy (in situ or pre-organophilization), and the individual or simultaneous removability of the model pollutants. The current study revealed that the applied low cost, in situ prepared clay mineral adsorbents are applicable in the removal of pollutants from thermal water.
\end{abstract}

Keywords: thermal water; phenol; humic acid; adsorption; clay mineral

\section{Introduction}

The elimination of organic compounds from used thermal water is an objective of increasing importance. A significant proportion of the thermal water sources contain phenolic type compounds and other organic materials such as polycyclic aromatic hydrocarbons and in many cases humates [1]. The composition of these water resources depends mostly on the mineral composition of the rocks which were in contact with the water [2]. Some of the most abundant water soluble pollutants are the different types of phenolic $\mathrm{OH}$ containing organic compounds (phenols). According to the Hungarian regulation (MSZ 1484-1:1992), the emission limit for phenols are $1 \mathrm{mg} \cdot \mathrm{L}^{-1}$. These compounds also show toxic effects on organisms such as tilapia (Oreochromis mossambicus) and bacteria (for example cyanobacteria) [1]. The toxic effect is well reflected in the case of tilapia: Although the LC50 (96 h 
exposure) value for tilapia is $\approx 30 \mathrm{mg} \cdot \mathrm{L}^{-1}$, the reproduction rate was $50 \%$ lowered at $2.85 \mathrm{mg} \cdot \mathrm{L}^{-1}$ phenol concentration [3-5].

The thermal water in the southern part of the Carpathian Basin generally contains humic acids and in some cases phenols. The amount of dissolved humic acid shows the highest value in low temperature thermal water. Furthermore, the humic acid to DOC (dissolved organic carbon) ratio decreases with increasing water temperature. This ratio is usually between 0.2 and 0.5 when the water temperature is $\approx 70{ }^{\circ} \mathrm{C}$, while at $40{ }^{\circ} \mathrm{C}$ the same ratio is between 0.5 and 0.75 [1].

Unfortunately, in some cases, the used thermal water cannot be repressed into the Earth's crust. Consequently, the evacuation into surface water is sometimes preferred. Nevertheless, salts and organic materials from the used thermal water can severely harm the surface waters' delicately balanced ecosystem. Therefore, a prior cleaning process is mandatory.

There are several methods for removing the aforementioned organic contaminants, such as membrane technology (filtration), biodegradation, advanced oxidation processes (AOPs) or adsorption methods [6]. Although AOPs are very efficient, they require very expensive equipment and the continuous functioning costs are high $[7,8]$.

Nowadays, due to their simplicity and in-situ implementation potential, several research groups have attempted to elaborate effective adsorption processes. Though the clay minerals are relatively inexpensive, their use is still limited due to the time and energy consuming synthesis of the organoclays. It would be a promising solution if the formation of organoclays and the adsorption process could be accomplished in a single step. During preliminary investigations, the swollen sodium montmorillonite was added to the polluted water, which was followed by the addition of the cationic surfactant in a pre-specified concentration based on the cation exchange capacity (CEC) of the clay [9-12]. According to the literature and our previous studies [11,13-15], the cation exchange capacity is in direct correspondence to the adsorption capacity. Salts and other compounds of the media also affected the adsorption [16].

The surface of sodium montmorillonite can be efficiently modified by cationic surfactants in water. Removing the organic molecules (like pesticides) have demonstrated that the efficiency of the adsorption depends on the organic cation saturation, i.e. on the surfactant content of the clay mineral. The adsorption capacity is related to the charge density, so the type of clay mineral is crucial [17]. In aqueous media, the charge balancing sodium ions are solvated and removed from the surface of the clay mineral lamellae, while negative charges will be available for other positively charged species, such as cations from cationic surfactants. The charge-replaceability of inorganic ions of the clay mineral can be characterized by the CEC value. It has been observed that there is a correlation between the lamella distance, the length of alkyl chain of the surfactant, and the removal efficiency [18,19]. Most of the effective adsorbents are expensive, so for the removal of frequent contaminants (such as benzene, toluene and phenol derivatives) inexpensive adsorbents should be prepared and examined.

The adsorption of phenol takes place on the surface of the clay mineral $[10,11,20]$, although only slightly (the adsorption capacity was between 0.2 and $0.75 \mathrm{mg} \cdot \mathrm{g}^{-1}$ ). The removal efficiency of phenol (concentrations were between 25 and $500 \mathrm{mg} \cdot \mathrm{L}^{-1}$ ) from aqueous solutions was tested using bentonite suspension at a $50 \mathrm{~g} \cdot \mathrm{L}^{-1}$ concentration. The adsorption equilibrium was reached within $10 \mathrm{~h}$, and the adsorption efficiency was between $0.2 \mathrm{mg}$ and $0.75 \mathrm{mg}$ adsorbed phenol with respect to $1 \mathrm{~g}$ adsorbent [21]. In a surfactant-free system, the $\mathrm{pH}$ dependence of adsorption was well demonstrated $[19,20]$. The organic cations change the hydrophilic nature of the montmorillonite to organophilic, and this makes them suitable for adsorbing different type of organic molecules from water $[20,21]$. Consequently, the behavior of simple in situ organophilic adsorbents is worth studying.

In our present study, the application of a one-step process, the influence of the mixing sequence and the $\mathrm{pH}$, the interaction of the two model compounds (phenol and sodium humate, which are representative compounds in the thermal water of Hungary) and their effects on the adsorption equilibrium were investigated. 


\section{Materials and Methods}

\subsection{Materials}

In all the adsorption experiments, high purity de-ionized water (Millipore Milli-Q) was used as the solvent. The total organic carbon (TOC) content of this water was less than 5 ppb. Phenol (PH) (MS-3D, puriss; $c_{\text {stock solution }}=2000 \mathrm{mg} \cdot \mathrm{L}^{-1}$ ) and humic acid sodium salt (SH) (Sigma-Aldrich, 95\%; $\mathrm{c}_{\text {stock solution }}=1000 \mathrm{mg} \cdot \mathrm{L}^{-1}$ ) were used as model pollutants.

Two natural clay minerals (Na-bentonite) were used throughout our experiments: Deriton (Unikén Ltd., Kecel, Hungary, CEC $=0.888 \mathrm{mmol} \cdot \mathrm{g}^{-1}$ ) and Kunipia-F (Kunimine Industries, Tokyo, Japan, JCSS, $3101 \mathrm{CEC}=1.15 \mathrm{mmol} \cdot \mathrm{g}^{-1}$ ). A 20,000 $\mathrm{mg} \cdot \mathrm{L}^{-1}$ clay mineral suspension was made from Milli-Q water and swelled for at least $24 \mathrm{~h}$ before use.

To promote flocculation, a cationic surfactant (hexadecyltrimethylammonium bromide (HTAB), Sigma-Aldrich, $95 \%$; $\mathrm{c}_{\text {stock solution }}=5000 \mathrm{mg} \cdot \mathrm{L}^{-1}$ ) was used in order to cover $100 \%$ of CEC of the clay minerals.

\subsection{Methods and Instrumentation}

Clay mineral suspension in combination with a surfactant was used as the adsorbent. HTAB was applied to enhance the flocculation and adsorption process. These experiments were performed in a Velp JLT6 jar-test apparatus. The changes in the concentration of organic contaminants were followed by an Agilent $8453 \mathrm{UV} /$ Vis spectrophotometer $\left(\lambda_{\text {detection PH }}=270 \mathrm{~nm}, \lambda_{\text {detection SH }}=300 \mathrm{~nm}\right)$. During the adsorption procedure, no new compounds were detected, so the concentration decrease of the target molecule (pollutant) could be easily followed. For the accurate determination of the concentration values, a baseline correction was used (Figure 1).

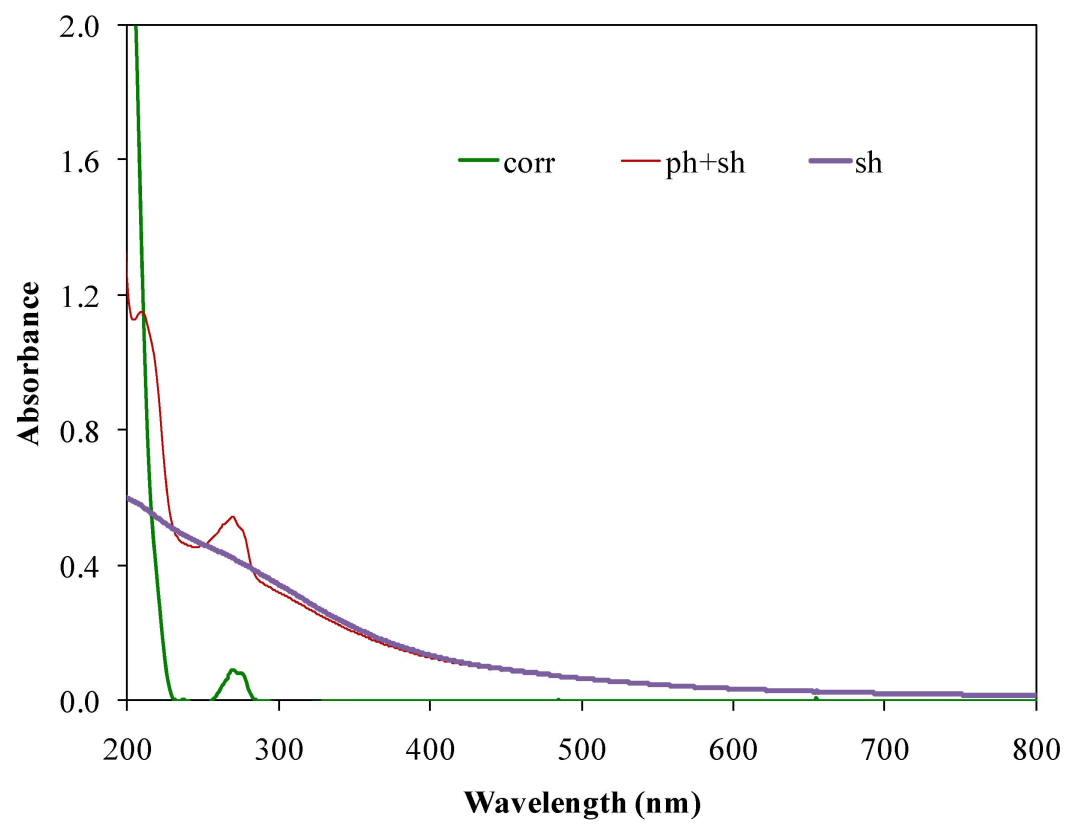

Figure 1. The spectrum of sodium humate with phenol $(\mathrm{PH}+\mathrm{SH})$, sodium humate $(\mathrm{SH})$ and the corrected spectrum of phenol (corr).

An INOLAB WTW pH 730 series type digital $\mathrm{pH} / \mathrm{mV}$ meter was used for the determination of the $\mathrm{pH}$ in the experimental setup. Before measurements were taken, the instrument was calibrated using the appropriate buffers. Samples were taken from the clear supernatant of the solution and then filtered with a Minisart-plus CA + GF prefilter membrane (0.45 $\mu \mathrm{m}$ pore size). 
The preparation of pre-organophilized adsorbent was carried out in a $1 \mathrm{~L}$ volumetric flask. The concentration of the clay mineral suspension was set to $10 \mathrm{~g} \cdot \mathrm{L}^{-1}$ and completed with hexadecyltrimethylammonium bromide at $100 \%$ of CEC. It was then kept at $60^{\circ} \mathrm{C}$ and stirred for $24 \mathrm{~h}$ followed by filtration and washing. Finally, the initial concentration was re-established in a volumetric flask $(1 \mathrm{~L})$ by adding the necessary amount of Milli-Q water. The adsorbent prepared in this way showed a much smaller flake size than the in situ organophilized adsorbent. However, the shelf life is much shorter (it cannot be held for an unlimited period).

The adsorption experiments were carried out as follows. The total sample volume was $500 \mathrm{~mL}$. The calculated amount of deionized water was stirred at $180 \mathrm{rpm}$ while the model compound was fed into the vessel. The initial concentration of $\mathrm{SH}$ was $16.7 \mathrm{mg} \cdot \mathrm{L}^{-1}$, while the $\mathrm{PH}^{\prime}$ s concentration was set to $10 \mathrm{mg} \cdot \mathrm{L}^{-1}$ for all the experiments. In Method 1 (in situ organophilized adsorbent), the clay mineral suspension was added to the solution, followed by the cationic surfactant, while in the case of Method 2 the pre-organophilized adsorbent was added (The preparation of the pre-organophilized adsorbent will be detailed later on) directly to the solution containing the chosen pollutants. The stirring was then slowed down to $40 \mathrm{rpm}$ and continued for $40 \mathrm{~min}$. The mixing cycle was followed by 20 min of sedimentation. Consequently, a solution sample was collected from the supernatant and then micro-filtered. The spectrum of the pollutants was measured as detailed above.

\section{Results and Discussion}

\subsection{Selection of the Clay Minerals}

The adsorption capacity itself is directly related to the charge density of clay mineral [11]. If the surface charge density is high, then the clay mineral is non-swellable, and, of course, the cations are not exchangeable [22,23]. Consequently, the CEC is small, because only the outer surface is available. In our experiments, a low-cost European and an acknowledged Japanese clay mineral were used.

These types of clay minerals (Deriton-CEC $0.888 \mathrm{mmol} \cdot \mathrm{g}^{-1}$ and Kunipia-F-1.15 mmol.g ${ }^{-1}$ ) were covered by a cationic surfactant (HTAB) at $100 \%$ of CEC. The added amount of clay was $500 \mathrm{mg}$ in each liter of solution. In these experiments, $16.7 \mathrm{mg} \cdot \mathrm{L}^{-1}$ was the $\mathrm{SH}^{\prime} \mathrm{s}$ starting concentration, and it was removed, applying in situ organophilization. Kunipia-F efficiently removed the SH, while Deriton achieved only $84 \%$ (see Figure 2a).

This result confirmed our expectations that the cation exchange capacity directly influenced the adsorption performances [11]. Based on these results, only Kunipia-F clay mineral was used to prepare the adsorbents in further experiments.

\subsection{Selecting the Proper Organophilization Methodology}

In the literature, the pre-organofilized adsorbents were widely investigated in the removal of organic pollutants by means of adsorption. Due to a growing concern about the usage of in situ prepared adsorbents, more and more publications are becoming available. The essence of the procedure consists in the formation of flakes, which should be removable by sedimentation $[17,18,24]$.

Consequently, it is necessary to examine these two methods in order to establish which one is more suitable for our target application (phenol and SH removal). Phenol (10 mg. $\left.\mathrm{L}^{-1}\right)$ was used as a model compound in these experiments, since phenolic compounds are quite frequent in real wastewater and thermal water, as already mentioned in the introduction $[1,4,5]$.

In both methods, the amount of clay mineral was $500 \mathrm{mg}$ in $1 \mathrm{~L}$ solution. The clay mineral was covered by HTAB at $100 \%$ of CEC. As shown by the experiment results (Figure $2 b$ ), the in situ organophilized adsorbent was capable of adsorbing a higher amount of phenol from the solution. The residual concentration of phenol was approximately $4.8 \mathrm{mg} \cdot \mathrm{L}^{-1}(48 \%$; the removal efficiency was $52 \%)$ via the in situ method, while the pre-prepared adsorbent was less efficient $(21 \%)$, as shown by the $7.9 \mathrm{mg} \cdot \mathrm{L}^{-1}(79 \%)$ residual phenol concentration. 


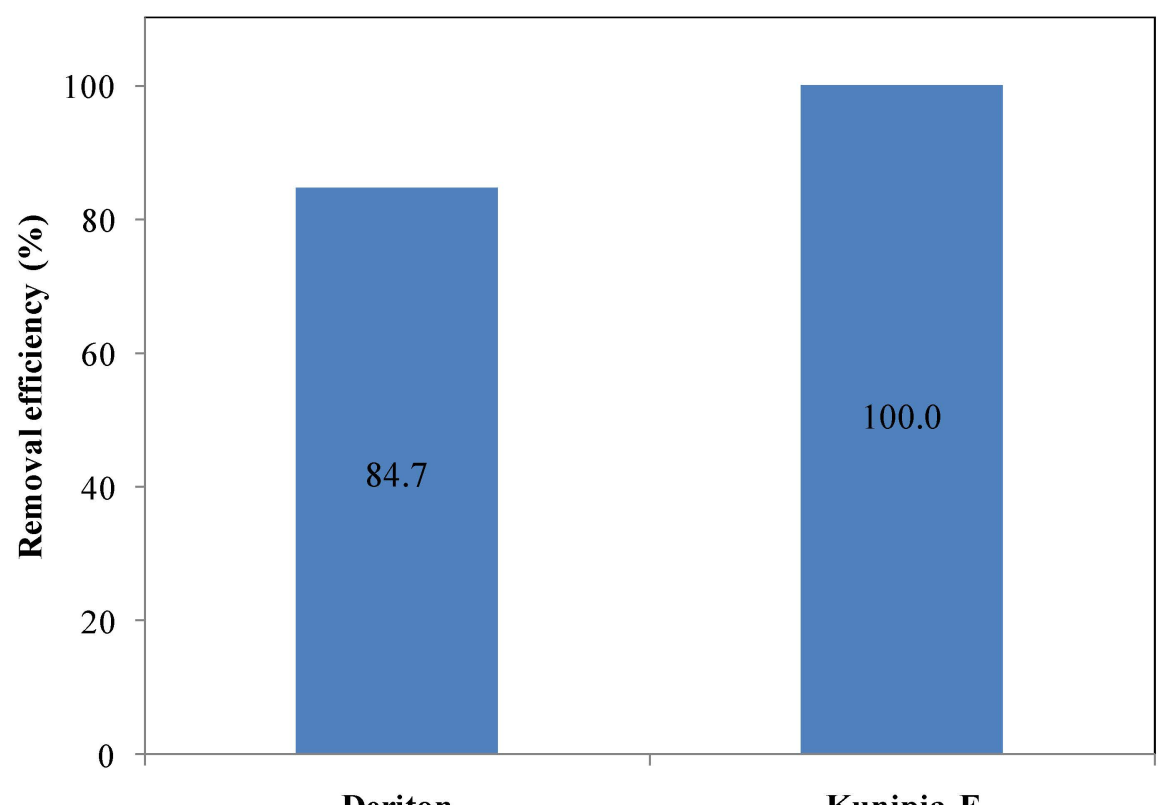

(a)

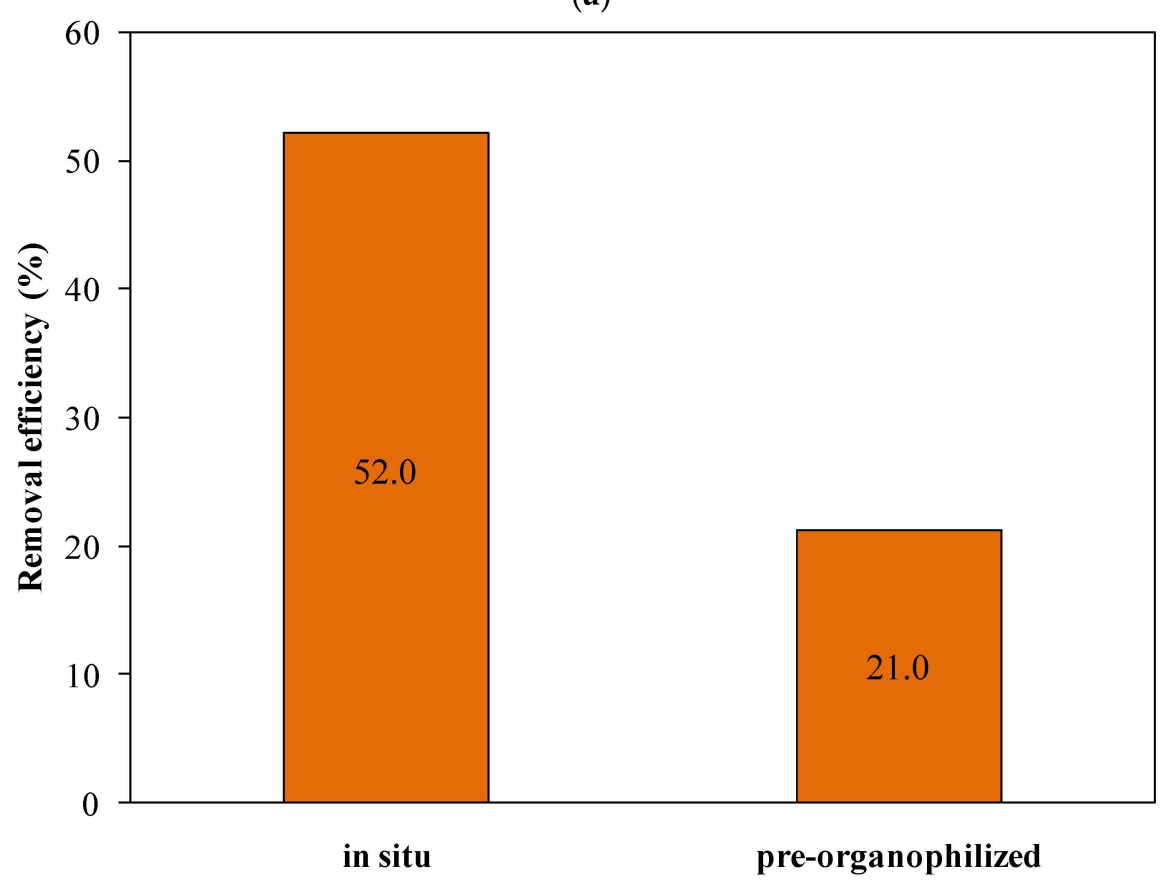

(b)

Figure 2. (a) Removal of sodium humate $\left(10 \mathrm{mg} \cdot \mathrm{L}^{-1}\right)$ by Kunipia-F and Deriton clay minerals; (b) removal of phenol $\left(10 \mathrm{mg} \cdot \mathrm{L}^{-1}\right)$ by two different adsorption methods (in situ made and pre-organofilized adsorbent).

Another advantage of the in situ adsorbents compared to the pre-prepared ones was that the latter one cannot be stored for a long time. Moreover, the in situ adsorbent is stable and immediately usable whenever required. Hence, in further experiments, only in situ adsorbents (based on swollen clay minerals) were used, and the following aspects were investigated:

- the competitive adsorption of HTAB

- the $\mathrm{pH}$ change during the adsorption process

- the input sequence of the pollutants, HTAB and the adsorbent 


\subsection{The Separate Removal of Model Pollutants}

3.3.1. The Impact of Instantaneous Intake of the Adsorbent—-the Possibility of Competitive Adsorption of HTAB

This experiment was carried out in order to confirm or to negate the existence of the competitive adsorption of HTAB. Experiment 1 (standard method, Figure 3) was implemented using the following addition sequence:

- (1) aqueous solution of the model pollutant;

- (2) swollen clay mineral;

- (3) HTAB.

Experiment 2 (sharp intake, Figure 3) was implemented using the following addition sequence:

- (1) solution with model pollutant;

- (2) swollen clay mineral containing HTAB.

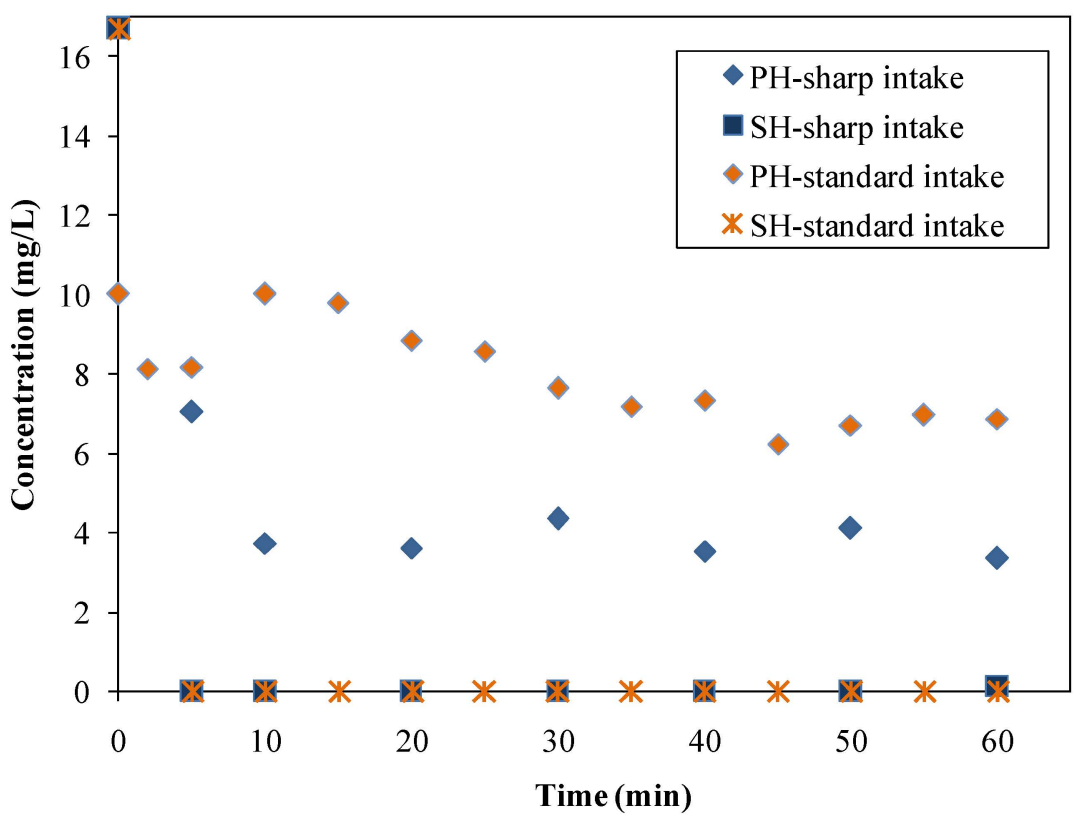

Figure 3. The concentration of model pollutants in the case of individual pollutant removal experiments

(PH: phenol; SH: sodium humate; in two examined conditions: (1) standard intake; (2) sharp intake).

If the presumed HTAB competitive adsorption exists, then the adsorption experiment results should differ (Experiment 1 vs. Experiment 2), because, in the case of Experiment 1, the clay mineral comes in contact with model pollutant and only after with the HTAB, while in the case of Experiment 2 the HTAB was already added to the swollen clay before adding to the pollutant solution. It was established that the equilibrium concentration of the pollutants was achieved:

- standard intake investigations: after $40 \mathrm{~min}$ in the case of phenol (although a slight concentration decrease was observed starting from the 10th min) and immediately in the case of SH;

- sharp intake investigations: after approximately $10 \mathrm{~min}$ in the case of phenol and immediately in the case of $\mathrm{SH}$.

Both of the considered experiments showed similar results in the case of SH (nearly complete removal), while for phenol the "sharp intake" method was found to be more efficient. Based on these experiments, it was concluded that there was a slight competition between the phenol and cationic 
surfactant in binding to the clay mineral's surface (Figure 3). This effect was observable only in the case of phenol. This is a very important aspect, because, if there is a specific dominant pollutant in a water, the application of the adsorption method should be by the means of "sharp intake" of the in-situ adsorbent.

\subsubsection{The Change of $\mathrm{pH}$ During Adsorption Processes}

The effect of the adsorbents' presence (clay mineral and cationic surfactant) on the $\mathrm{pH}$ was followed in these experiment series. The initial $\mathrm{pH}$ value of deionized water was 6.9. In the clay suspension, the $\mathrm{pH}$ increased with 1 unit compared to the deionized water (Table 1).

Table 1. $\mathrm{pH}$ values measured in the studied samples.

\begin{tabular}{cc}
\hline Sample & pH \\
\hline Milli-Q water & 6.9 \\
Clay Mineral, Kunipia $\left(500 \mathrm{mg} \cdot \mathrm{L}^{-1}\right)$ & 7.9 \\
Cationic surfactant, HTAB-5.75 $10^{-4} \mathrm{~mol} \cdot \mathrm{dm}^{-3}$ & 5.9 \\
In situ adsorbent & 7.5 \\
\hline
\end{tabular}

The cationic surfactant (HTAB) showed a slightly acidic $\mathrm{pH}$ value of 5.9. The $\mathrm{pH}$ of the suspension that was involved in the in situ prepared adsorbent was finally 7.5.

The investigation of the $\mathrm{pH}$ change was performed in a "single pollutant system." The effect of the stirring was also taken into account, and it was found to be negligible ( $0.04 \mathrm{pH}$ unit). Therefore, the experiments were performed according to the in situ adsorbent preparation (Figure 4). From Figure 4, it is clearly visible that the variation in $\mathrm{pH}$ was different for the two individual pollutants throughout the whole experiment. In the case of phenol, the initial $\mathrm{pH}$ was close to neutral $(\approx 7)$. This value then increased after $10 \mathrm{~min}$ and was followed by a slow decrease until the end of the adsorption process (40 min). After that period (in the sedimentation stage), a stationary value was obtained (7.3). The maximum value at the end of the $\mathrm{pH}$ increase section was the same as the $\mathrm{pH}$ of the initial adsorbent suspension (the $\mathrm{pH}$ of the in situ adsorbent was 7.5- see Table 1). In the case of the sodium humate solution, the initial $\mathrm{pH}$ value was 7.76, which decreased slowly until the 40th min of the experiment when the value finally reached 7.6.

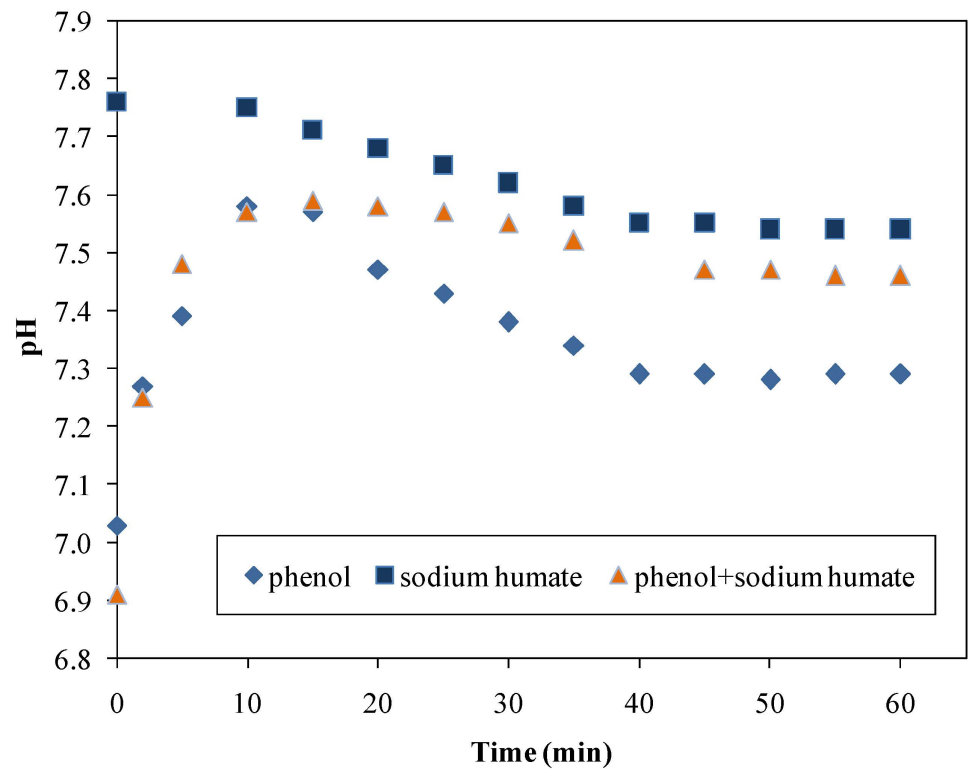

Figure 4. The examination of the $\mathrm{pH}$ variation during adsorption in the single pollutant and in the combined system. 
The concentration of model compounds was also measured simultaneously (Figure 3) with the $\mathrm{pH}$. The concentration of phenol showed an intensive fluctuation for $10 \mathrm{~min}$ and then decreased continuously until the 45th min. Based on the shown results, the adsorption equilibrium of phenol was reached slowly (in $45 \mathrm{~min}$ ), while in the case of sodium humate this was immediate (Figure 3; phenol: PH-standard intake and sodium humate: SH-standard intake). The $\mathrm{pH}$ value of the initial solution changes for two reasons: (1) Adsorbent clay and surfactant were simultaneously present; and (2) the organic molecules were "extracted" from the solution phase by the adsorbent by means of the initial adsorption.

\subsection{Experiments with Multiple Model Pollutants}

\subsubsection{The Impact of Instantaneous Intake of Adsorbent}

In the natural thermal water, several types of organic compounds can be found. Among them, phenolic compounds and humic acids are often present simultaneously [1]. Consequently, their combined removal is an actual challenge. The main goal in these experiments was the same as in Section 3.3.1.

Implementation of Experiment 1 (standard method): solution with 2 model pollutants + swollen clay mineral + HTAB. The concentration of phenol was constant between 5-35 min. A slight concentration decrease was then noticed until the 45th min (with minor fluctuation), and it became constant until the end of the experiment (Figure 5). The concentration of sodium humate decreased continuously until the 15 th min, and showed a slight increase at the 40 th min.

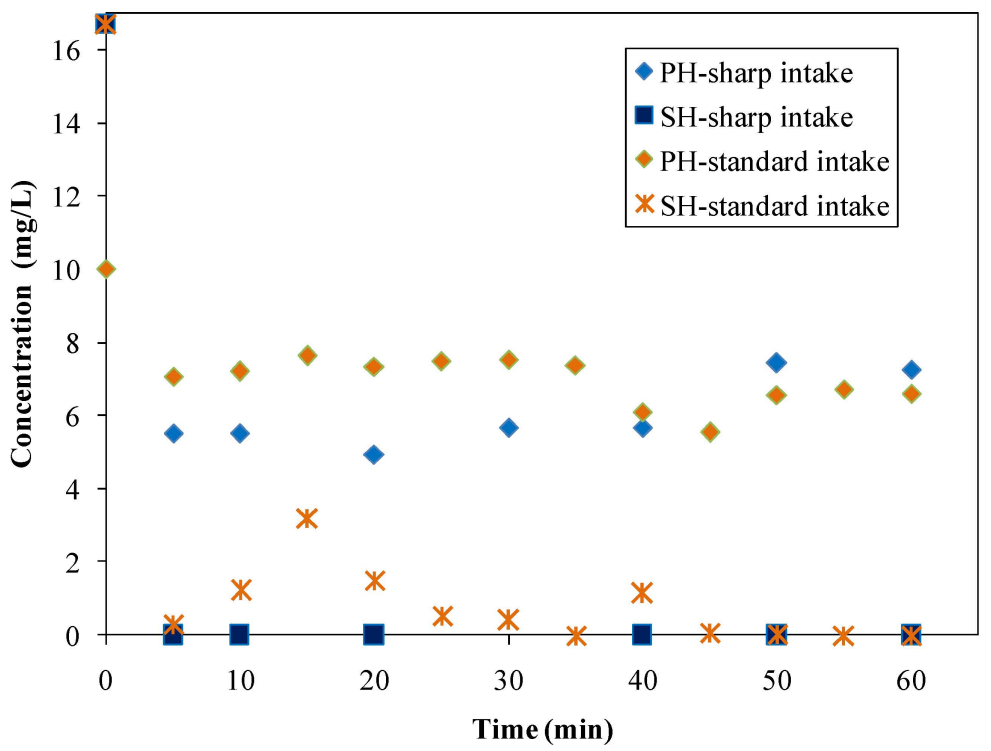

Figure 5. The concentration changes of model pollutants in the combined method, in the case of conventional and sharp adsorbent dosage, and during the monitoring of the $\mathrm{pH}(\mathrm{PH}$ : phenol; SH: sodium humate).

Implementation of Experiment 2 (sharp intake): solution with 2 model pollutants + (swollen clay mineral + HTAB - pre-prepared). The adsorption equilibrium of two model compounds were simultaneously examined in the case of instantaneous input of the adsorbent. The following results were found. The equilibrium concentration of phenol (Figure 5) (contrary to the case of single pollutant (Figure 3) -in Section 3.3.1) was reached very quickly.

Considering the final equilibrium concentration of the pollutants, we can affirm that both approaches resulted in a similar removal efficiency of the pollutants (PH: 36\%-standard intake vs. $32 \%$ - sharp intake; $\mathrm{SH}$ : $99 \%$ —standard intake vs. $99 \%$-sharp intake), meaning that, in a complex 
adsorption system with multiple pollutants, the HTAB does not compete for the clay mineral's surface with the organic pollutants.

It should be noted here that in Section 3.3.1 (single pollutant system) the phenol removal efficiency was $60 \%$ (sharp intake) and 34\% (standard intake) respectively, while in the present case it was $32 \%$ and $36 \%$, respectively. This shows that, in polluted waters with two or more pollutants, $\mathrm{SH}$ removal was almost complete in all cases studied, whereas for $\mathrm{PH}$ the removal efficiency was lower during the sharp intake tests and similar during the standard methods in the presence of $\mathrm{SH}$.

\subsubsection{The $\mathrm{pH}$ Changes during the Adsorption}

The $\mathrm{pH}$ changes were previously evaluated for the adsorption of individual compounds (Section 3.3.2). The characteristic $\mathrm{pH}$ evolution curve was different in the case of each compound. Consequently, it was necessary to examine the combined behavior of the chosen model compounds.

In these experiments, the changes in both concentration and the $\mathrm{pH}$ of the two model compounds were followed concomitantly. The $\mathrm{pH}$ curve of the combined method did not follow the individual curves of the pollutants. During the removal of the two compounds, the initial section of the curve was similar to the one registered for phenol when the $\mathrm{pH}$ value increased from 6.9 to 7.6 (Figure 4). After $15 \mathrm{~min}$, the characteristic of the $\mathrm{pH}$ curve approached to the one measured for sodium humate. After $40 \mathrm{~min}$, the $\mathrm{pH}$ value stabilized at $\mathrm{pH} \approx 7.5$. The shown maximum of the registered $\mathrm{pH}$ curve refers to the equilibrium of phenol adsorption in the case of two different-single and combined-method.

Along with the $\mathrm{pH}$ changes, the concentration changes of the two examined compounds were also examined in this study (Figure 5). The concentration of sodium humate slowly reaches the equilibrium value, and the curve shows two maxima. The second maximum is at $40 \mathrm{~min}$ when the concentration of phenol reaches a minimum.

\subsection{Changing the Input Sequence}

In this series of experiments, the input order of the model pollutants and the components of the adsorbent were investigated (Figure 6).

Because the order of the in-situ adsorbent components is optional, it is worth examining which is optimal for the adsorption in terms of efficiency and equilibrium concentration. The behavior of each component (such as model compounds and adsorbent) and their affinity to each other can be tested during the adsorption by this method. The practical applicability of this experiment relies on the fact that, if the order of the addition of the pollutants and the adsorbent is known, different types of thermal waters can be treated simultaneously (e.g., one containing dominantly phenols, and the other one, humic acids).

In the first experiment in this series, the input sequence was: 1: phenol; 2: sodium humate; 3: clay mineral; 4: cationic surfactant (Figure 7).

Accordingly, in this case, the following results were obtained:

(i) The half amount of the introduced $\mathrm{SH}$ was adsorbed in $5 \mathrm{~min}$.

(ii) Between the 10th and 20th min, a smaller fraction of the adsorbed phenol desorbed from the organoclay's surface.

(iii) After $20 \mathrm{~min}$, the phenol's concentration was stationary $\left(\approx 7 \mathrm{mg} \cdot \mathrm{L}^{-1}\right)$, and, surprisingly, sodium humate was not completely adsorbed during this experiment.

(iv) The equilibrium concentration of $\mathrm{SH}$ was $1-2 \mathrm{mg} \cdot \mathrm{L}^{-1}$, but between 5 and $10 \mathrm{~min}$ a fluctuation was observed in the concentration values. Typically, the increase of the $\mathrm{SH}$ concentration showed an opposing behavior compared to the concentration change of phenol. 


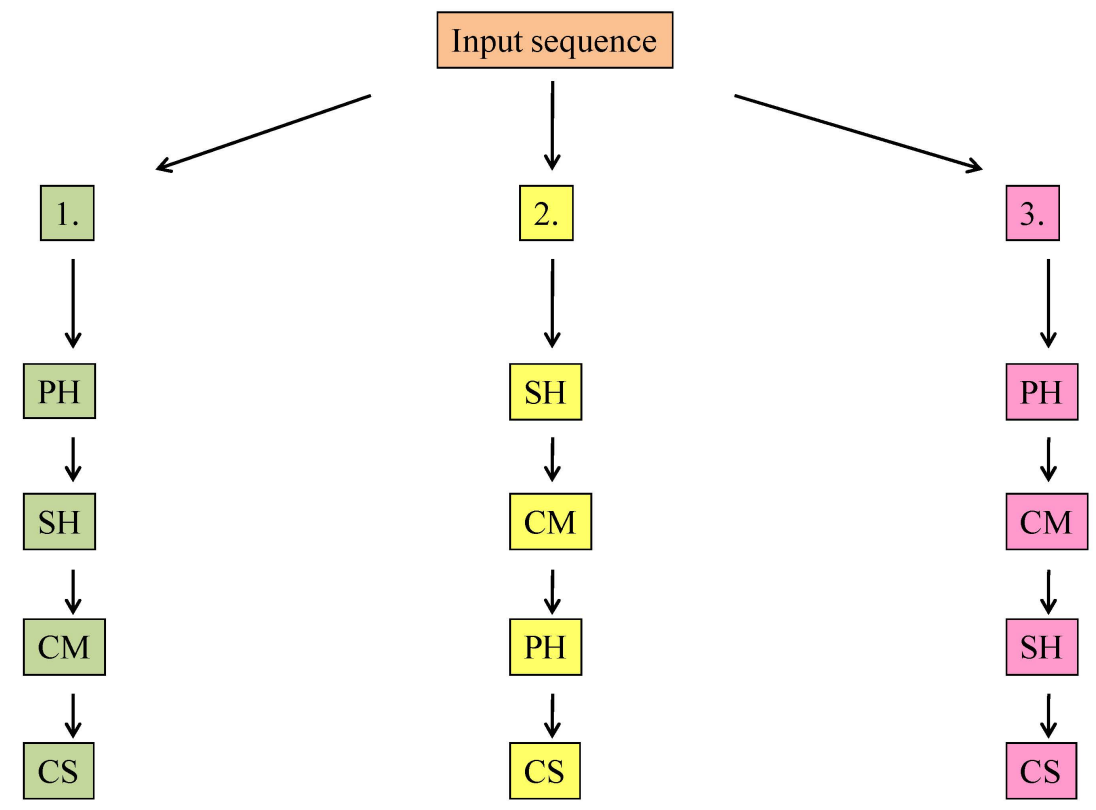

Figure 6. Changing the input sequence; PH: phenol; SH: sodium humate; CM: clay mineral; CS: cationic surfactant.

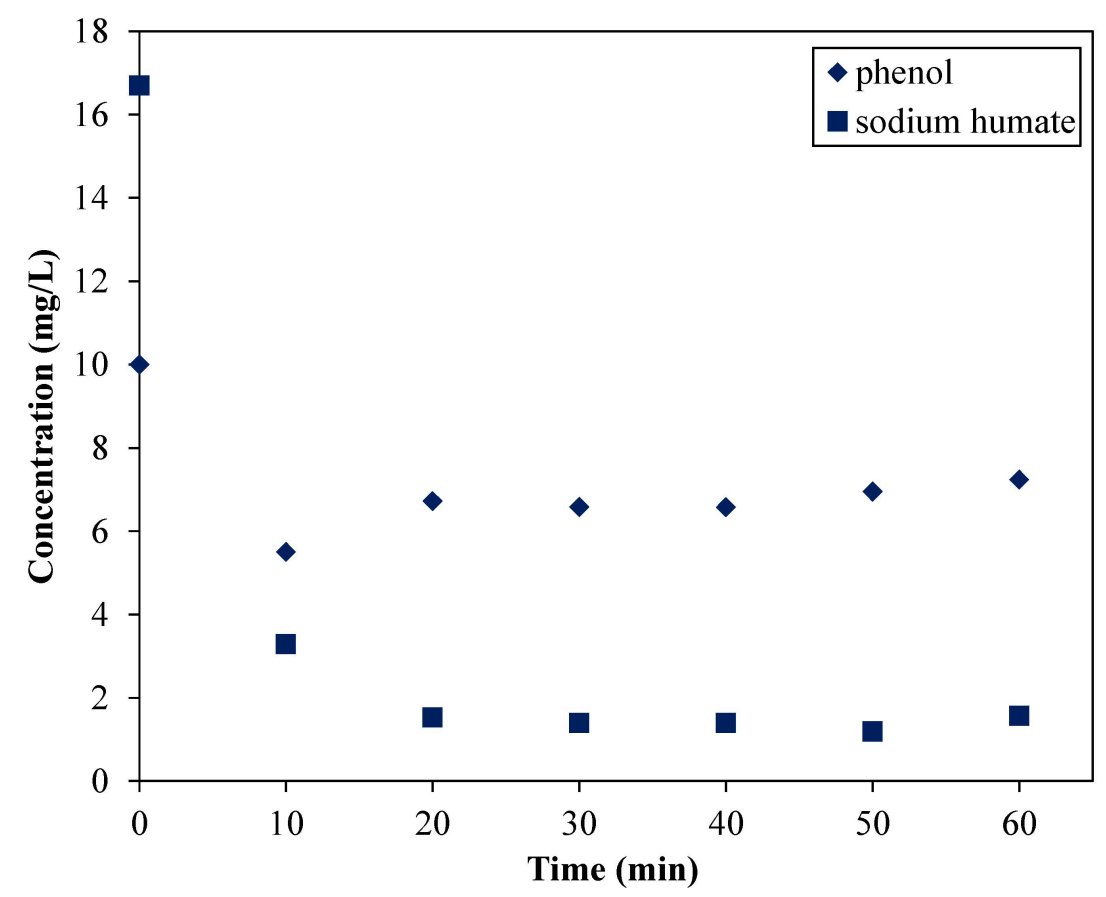

Figure 7. The effect of changing the input sequence-in this case, the following order was implemented 1: phenol; 2: sodium humate; 3: clay mineral; 4: cationic surfactant.

In the second experiment, the next order was applied: 1: sodium humate; 2: clay mineral; 3: phenol; 4: cationic surfactant (Figure 8).

The system behaved similarly to the previous case. The concentration of sodium humate decreased immediately, and it was constant until the 40th min, at which point it increased until the end of the experiment. The phenol concentration reached the equilibrium value after $30 \mathrm{~min}$, and it was constant for $20 \mathrm{~min}$, and was followed by a slow increase. 
The third measurement was applied in the following order: 1: phenol; 2: clay mineral; 3: sodium humate; and, at last, the cationic surfactant (Figure 9). When the dosage of clay mineral appeared, the phenol alone was already present in the solution. This was followed by the addition of sodium humate-the adsorption of phenol showed no particular result $\left(c_{\text {phenol }} \approx 6 \mathrm{mg} \cdot \mathrm{L}^{-1}\right)$, and the adsorption of $\mathrm{SH}$ was worse than the other cases. The $\mathrm{SH}$ dissolved back into the solution continuously after the initial adsorption. Thus, this method proved to be inefficient. Based on these experiments, the presence of sodium humate positively influences the adsorption and establishment of the equilibrium concentration of phenol.

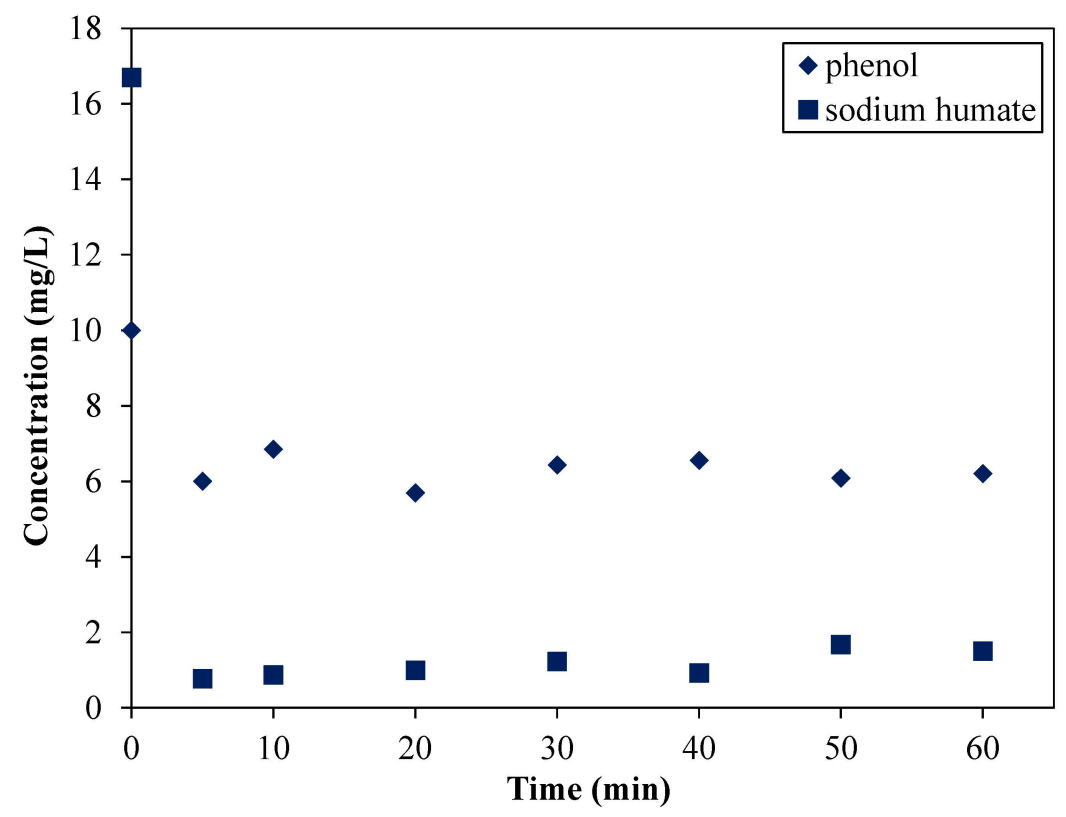

Figure 8. The effect of changing the input sequence-in this case, the following order was implemented 1: sodium humate; 2 : clay mineral; 3: phenol; 4: cationic surfactant.

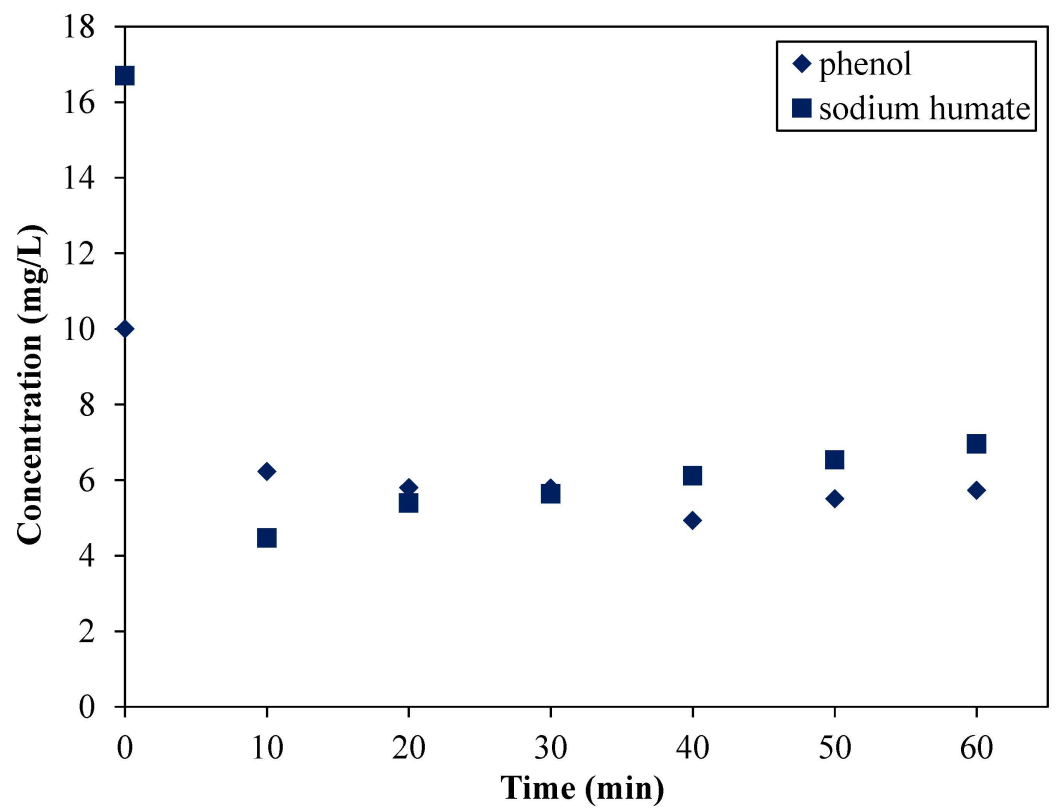

Figure 9. The effect of changing the input sequence-in this case, the following order was implemented 1: phenol; 2: clay mineral; 3: sodium humate; 4 : cationic surfactant. 


\section{Conclusions}

Based on our experiments, it can be concluded that in-situ organophilized clays can be efficient in the removal of organic compounds of low concentrations, such as phenols and humic acid. It was established that the simultaneous removal of two pollutants is possible, but the mixing sequence is crucial. The best removal yield was achieved when the model pollutants were in the initial solution, the clay mineral added afterward, and the cationic surfactant thereafter. It was determined that the subsequent addition (after the addition of the adsorbent) of sodium humate into the adsorption system causes a "single pollutant" behavior. In this case, there is no competition between the model compounds, while the sodium humate acts as a weak adsorption inhibitor. However, this inhibition does not exist in the case of the standard method (in situ adsorbent-Sections 3.3.1 and 3.4.1), but in the sharp intake method only. Accordingly, it is not necessary to remove the humic substances before the removal of phenolic compounds. Combined and simultaneous removal of sodium humate and phenol accelerates the establishment of an equilibrium concentration of phenol. Furthermore, it was additionally concluded that the rapid addition of the adsorbents (clay mineral and cationic surfactant simultaneously) was advantageous. This is an important aspect if a real thermal water treatment is to be considered via adsorption in a batch reactor.

Acknowledgments: The Kunipia-F sodium bentonite was received as a free sample from Kunimine Industries Co., Ltd., Japan. The authors express their gratitude towards the manufacturer. Furthermore, TÁMOP-4.2.2.A-11/1/KONV-2012-0047 is also thanked for the financial support given.

Author Contributions: Emese Szabó is the primary author of the paper. She performed the adsorption measurments and participated in the preparation of the manuscript; Zsolt Pap is the supervisor of the entire experiment and contributed to the prepration of the manuscript as the corresponding author; Gergő Simon-he performed the "input sequence" related measurments and interpreted the experimental data; András Dombi played an important role in the preparation of the entire experiment, contributed significantly to the improvement of the manuscript, and provided financial support for the experiments; Lucian Baia-His role was in the data interpretation and provided the methodology for supplementary measurments; Hernádi Klára contributed significantly to the improvement of the manuscript and provided the necessary funds for the experiments.

Conflicts of Interest: The authors declare no conflict of interest.

\section{References}

1. Kárpáti, Z.; Sajgó, C.; Vető, I.; Klopp, G.; Horváth, I. Organic matter in thermal waters of the Pannonian Basin-A preliminary report on aromatic compounds. Org. Geochem. 1999, 30, 701-712.

2. Pauwels, H.; Fouillac, C.; Goff, F.; Vuataz, F.D. The isotopic and chemical composition of $\mathrm{CO}_{2}$-rich thermal waters in the Mont-Dore region (Massif-Central, France). Appl. Geochem. 1997, 12, 411-427. [CrossRef]

3. Saha, N.C.; Bhunia, F.; Kaviraj, A. Toxicity of Phenol to Fish and Aquatic Ecosystem. Environ. Contam. Toxicol. 1999, 63, 195-202. [CrossRef]

4. Megharaj, M.; Pearson, H.W.; Venkateswarlu, K. Toxicity of phenol and three nitrophenols towards growth and metabolic activities of Nostoc linckia, isolated from soil. Environ. Contam. Toxicol. 1991, 21, 578-584. [CrossRef]

5. Abdollahi, M.; Hassani, S.; Derakhshani, M. Phenol. In Encyclopedia of Toxicology, 3rd ed.; Wexler, P., Ed.; Elsevier Academic Press: Amsterdam, The Netherland, 2014; pp. 871-873.

6. Stanisavljevic, M.; Nedic, L. Removal of phenol from industrial wastewaters by horseradish (Cochlearia armoracia L) peroxidase. Facta Univ. Ser. Work. Living Environ. Prot. 2004, 2, 345-349.

7. Hu, C.; Wang, Y.; Tang, H. Destruction of phenol aqueous solution by photocatalysis or direct photolysis. Chemosphere 2000, 41, 1205-1209.

8. Ilisz, I.; Dombi, A.; Mogyorósi, K.; Farkas, A.; Dékány, I. Removalof 2-chlorophenol from water by adsorption combined with $\mathrm{TiO}_{2}$ photocatalysis. Appl. Catal. B Environ. 2002, 39, 247-256. [CrossRef]

9. Shen, Y. Removal of phenol from water by adsorption-flocculationusing organobentonite. Water Res. 2002, 36, 1107-1114. [CrossRef]

10. Ma, J.; Zhu, L. Removal of phenols from water accompanied withsynthesis of organobentonite in one-step process. Chemosphere 2007, 68, 1883-1888. [CrossRef] [PubMed] 
11. Szabo, E.; Vajda, K.; Vereb, G.; Dombi, A.; Mogyorosi, K.; Abraham, I.; Majer, M. Removal of organic pollutants in model water and thermal wastewater using clay minerals. J. Environ. Sci. Health Part A 2011, 46, 1346-1356. [CrossRef] [PubMed]

12. Sanchez-Martin, M.J.; Dorado, M.C.; Hoyo, C.; Rodriguez-Cruz, M.S. Influence of clay mineral structure and surfactant nature on the adsorption capacity of surfactants by clays. J. Hazard. Mater. 2008, 150, 115-123. [CrossRef] [PubMed]

13. Xi, Y.; Mallavarapu, M.; Naidu, R. Preparation, characterization of surfactants modified clay minerals and nitrate adsorption. Appl. Clay Sci. 2010, 48, 92-96. [CrossRef]

14. Wiles, M.C.; Huebner, H.J.; McDonald, T.J.; Donnelly, K.C.; Phillips, T.D. Matrix-immobilized organoclay for the sorption of polycyclic aromatic hydrocarbons and pentachlorophenol from groundwater. Chemosphere 2005, 59, 1455-1464. [CrossRef] [PubMed]

15. Senturk, H.B.; Ozdes, D.; Gundogdu, A.; Duran, C.; Soylak, M. Removal of phenol from aqueous solutions by adsorption onto organomodified Tirebolu bentonite: Equilibrium, kinetic and thermodynamic study. J. Hazard. Mater. 2009, 172, 353-362. [CrossRef] [PubMed]

16. Szabó, E.; Pap, Z.; Dombi, A.; Hernádi, K.; Baia, L.; Simon, G. Important aspects on the removal of humic acid and phenolic compounds with clay minerals. "Synergism provided by the pollutants, efficiency given by the media". Water Air Soil Pollut. 2014, 225, 1888-1897.

17. Sanchez-Martin, M.J.; Rodriguez-Cruz, M.S.; Andrades, M.S.; Sanchez-Camazano, M. Efficiency of different clay minerals modified with a cationic surfactant in the adsorption of pesticides: Influence of clay type and pesticide hydrophobicity. Appl. Clay Sci. 2006, 31, 216-228. [CrossRef]

18. Liu, R.; Frost, R.L.; Martens, W.N.; Yuan, Y. Synthesis, characterization of mono, di and tri alkyl surfactant intercalated Wyoming montmorillonite for the removal of phenol from aqueous systems. J. Colloid Interface Sci. 2008, 327, 287-294. [CrossRef] [PubMed]

19. Tombácz, E.; Szekeres, M. Colloidal behavior of aqueous montmorillonite suspensions: The specific role of $\mathrm{pH}$ in the presence of indifferent electrolytes. Appl. Clay Sci. 2004, 27, 75-94.

20. Banat, F.A.; Al-Bashir, B.; Al-Asheh, S.; Hayajneh, O. Adsorption of phenol by bentonite. Environ. Pollut. 2000, 107, 391-398. [CrossRef]

21. Ocampo-Perez, R.; Leyva-Ramos, R.; Mendoza-Barron, J.; Guerrero-Coronado, R.M. Adsorption rate of phenol from aqueous solution onto organobentonite: Surface diffusion and kinetic models. J. Colloid Interface Sci. 2011, 364, 195-204. [CrossRef] [PubMed]

22. Stanković, N.; Logar, M.; Luković, J.; Pantić, J.; Miljević, M.; Babić, B.; Radosavljević-Mihajlović, A. Characterization of bentonite clay from "Greda" deposit. Process. Appl. Ceram. 2011, 5, 97-101. [CrossRef]

23. Neumann, M.G.; Gessner, F.; Schmitt, C.C.; Sartorio, R. Influence of the layer charge and the clay particle size on the interactions between the cationic dye methylene blue and clays in an aqueous suspension. J. Colloid Interface Sci. 2002, 255, 254-259. [CrossRef] [PubMed]

24. Churchman, G.J. Formation of complexes between bentonite and different cationic polyelectrolytes and their use as sorbents for non-ionic and anionic pollutants. Appl. Clay Sci. 2002, 21, 177-189. [CrossRef]

(c) 2016 by the authors; licensee MDPI, Basel, Switzerland. This article is an open access article distributed under the terms and conditions of the Creative Commons by Attribution (CC-BY) license (http://creativecommons.org/licenses/by/4.0/). 